\title{
Parametric optimization and process capability analysis for machining of nickel-based superalloy
}

\author{
Munish Kumar Gupta ${ }^{1} \cdot$ Mozammel Mia ${ }^{2}$ Catalin I. Pruncu ${ }^{3,4} \cdot$ Wojciech Kapłonek ${ }^{5} \cdot$ Krzysztof Nadolny $^{5}$. \\ Karali Patra ${ }^{6} \cdot$ Tadeusz Mikolajczyk $^{7} \cdot$ Daniil Yu. Pimenov $^{8}$ (D) $\cdot$ Murat Sarikaya $^{9} \cdot$ Vishal S. Sharma $^{10}$
}

Received: 11 November 2018 / Accepted: 6 February 2019 / Published online: 4 March 2019

(C) The Author(s) 2019

\begin{abstract}
The manufacturing of parts from nickel-based superalloy, such as Inconel-800 alloy, represents a challenging task for industrial sites. Their performances can be enhanced by using a smart cutting fluid approach considered a sustainable alternative. Further, to innovate the cooling strategy, the researchers proposed an improved strategy based on the minimum quantity lubrication (MQL). It has an advantage over flood cooling because it allows better control of its parameters (i.e., compressed air, cutting fluid). In this study, the machinability of superalloy Inconel- 800 has been investigated by performing different turning tests under MQL conditions, where no previous data are available. To reduce the numerous numbers of tests, a target objective was applied. This was used in combination with the response surface methodology $(\mathrm{RSM})$ while assuming the cutting force input $\left(F_{c}\right)$, potential of tool wear $\left(\mathrm{VB}_{\max }\right)$, surface roughness $(R a)$, and the length of tool-chip contact $(L)$ as responses. Thereafter, the analysis of variance (ANOVA) strategy was embedded to detect the significance of the proposed model and to understand the influence of each process parameter. To optimize other input parameters (i.e., cutting speed of machining, feed rate, and the side cutting edge angle (cutting tool angle)), two advanced optimization algorithms were introduced (i.e., particle swarm optimization (PSO) along with the teaching learning-based optimization (TLBO) approach). Both algorithms proved to be highly effective for predicting the machining responses, with the PSO being concluded as the best amongst the two. Also, a comparison amongst the cooling methods was made, and MQL was found to be a better cooling technique when compared to the dry and the flood cooling.
\end{abstract}

Mozammel Mia

mozammelmiaipe@gmail.com

Wojciech Kapłonek

wojciech.kaplonek@tu.koszalin.pl

Munish Kumar Gupta

munishguptanit@gmail.com; munishguptae7876@cumail.in

Catalin I. Pruncu

c.pruncu@imperial.ac.uk

Krzysztof Nadolny

krzysztof.nadolny@tu.koszalin.pl

Karali Patra

kpatra@iitp.ac.in

Tadeusz Mikolajczyk

tami@utp.edu.pl

Daniil Yu. Pimenov

danil_u@rambler.ru

Murat Sarikaya

msarikaya@ sinop.edu.tr

Vishal S. Sharma

sharmavs@nitj.ac.in
1 Department of Mechanical Engineering, Chandigarh University, Gharuan, Punjab, India

2 Mechanical and Production Engineering, Ahsanullah University of Science and Technology, Dhaka 1208, Bangladesh

3 Mechanical Engineering, Imperial College London, Exhibition Rd., London SW7 2AZ, UK

4 Mechanical Engineering, School of Engineering, University of Birmingham, Birmingham B15 2TT, UK

5 Department of Production Engineering, Faculty of Mechanical Engineering, Koszalin University of Technology, Racławicka 15-17, 75-620 Koszalin, Poland

6 Department of Mechanical Engineering, Indian Institute of Technology Patna, Bihta, Patna 801103, India

7 Department of Production Engineering, UTP University of Science and Technology, Al. prof. S. Kaliskiego 7,

85-796 Bydgoszcz, Poland

8 Department of Automated Mechanical Engineering, South Ural State University, Lenin Prosp. 76, Chelyabinsk 454080, Russia

9 Department of Mechanical Engineering, Sinop University, Sinop, Turkey

10 Department of Industrial \& Production Engineering, Dr B R Ambedkar National Institute of Technology, Jalandhar 144011, India 
Keywords Inconel-800 $\cdot \mathrm{MQL} \cdot$ Optimization · Sustainable machining $\cdot$ PSO $\cdot$ TLBO

\section{Introduction}

Nowadays, a great opportunity has arisen to produce robust parts for aerospace and the turbine sector with advanced performances (high mechanical strength at elevated temperatures and high resistance against corrosion) made of nickel-based superalloys (e.g., Inconel-800) [1] and titanium-based superalloys (e.g., Ti-6Al-4V) [2]. However, during machining processes, they raise challenges because of high toughness, low heat transfer coefficient, and very poor work hardening [3]. These later features obstruct the efficiency and generate moderate surface quality; in addition, they bring down the manufacturing time and increase cost. They even require careful environmental consideration, for example, on human health and safety. To increase the proficiency, a fundamental understanding is required that permits extending the cutting speed, keeping for longer tool life integrity, and controlling the scrap [4].

The nickel-based superalloy's machining ability depends on numerous input factors; amongst them, suitable lubrication (e.g., coolants) is the critical one [5]. It can have a major contribution to the total costs of production [6]. Furthermore, in this process, a suitable lubrication permits controlling the surface integrity characteristics and extends the tool life; however, its constituents are harmful to the environment [7]. Scientists started to overcome the cutting fluid concerns. They propose a sustainable solution while reducing and/or eliminating the use of cutting fluids by applying innovative methods (i.e., dry and minimum quantity lubrication (MQL) strategy) [8].

Dry machining that is an alternative to the classical process has partial benefits with a lot of drawbacks in terms of surface finishing and tool wear $[9,10]$. The sticking progress that occurs is often generated by a combination between low modulus of elasticity and weak heat transfer coefficient along with the chemical bonds' affinity that create a barrier on dry manufacturing of Inconel alloy [11]. Similarly, in the MQL condition, the lubrication is performed under an optimized manner within a controlled mixture of compressed air and limited cutting fluids $[12,13]$. Kamata and Obikawa [14] confirmed greater surface quality when turning experiments were conducted on the Inconel-718 alloy using MQL conditions. They noted a big improvement on machining cost when comparing to dry or wet machining. This strategy (MQL) was a valuable solution for machining by turning Inconel-725 alloys. It demonstrates efficiency in the reduction of cutting forces, improvement of surface roughness, and ensuring higher integrity for the tools as shown by Tazehkandi et al. [11]. The research performed by Pusavec et al. $[15,16]$ using the Inconel-718 alloys revealed that application of MQL can reduce the cutting forces, tool wear, and chip breakability along with the increased productivity.
Tazehkandi et al. [17] developed spray techniques to further increase the machining performances when manufacturing the Inconel-706. Overall, a carefully application of MQL when used the turning routine proved its beneficial results as decreasing tool wear activity, controlling the cutting forces, obtaining a constant cutting temperature, and higher surface quality. The turning performance of Inconel-800 superalloys depends mainly on controlling its process parameters. Therefore, the ideal procedure is obtained by embedding a suitable optimization strategy for selecting the best parameters [18].

Some traditional optimization techniques (geometric programming, nonlinear programming, sequential programming, goal programming, dynamic programming, etc.) were introduced to obtain the best features of process parameters [19]. However, the proposed strategies generate only a local optimal combination with limited accuracy and robustness risk. Moreover, the actual algorithms are very limited operationally for complex and nonlinear problems where it is required to easily manage the input parameters and to obtain qualitative output responses [20,21].

Novel advanced strategies offer consistent solution to eliminate these incompatibilities. Thus, some powerful metaheuristic algorithms, namely, particle swarm optimization (PSO), genetic algorithm (GA), artificial bee colony (ABC), teaching learning-based optimization (TLBO), etc., were integrated in order to optimize machining parameters [22-25]. Although the meta-heuristic algorithms perform better than traditional optimization algorithms, they are subjected to several disadvantages. The major disadvantage of these algorithms originated from insufficiency of achieving the global optimum solution because they do not have the ability to obtain the optimum parameters for the algorithm's simulation. The most prominent approach (i.e., GA) is an evolutionary optimization technique. This technique can generate a near optimal process within a complex manner problem formed from numerous numbers of variables and constraints. Its limitation is determined by the obstruction to achieve an optimum manageable parameter once determined the crossover and $\mathrm{mu}-$ tation rates. In the same manner, $\mathrm{ABC}$ can encounter some challenges identifying the optimum balance between the number of bees (i.e., engaged in the process, the scout and/or onlookers) and its limit. Architectural modifications and hybridization can increase further the complexity [24]. A smart optimization technique using less parameters in the algorithms may enable achieving suitable control of manufacturing process parameters.

The meta-heuristic algorithms (i.e., particle swarm optimization (PSO) and/or teacher learning-based optimization (TLBO)) can provide greater functionality for machining 
process control. It permits rapid convergences toward the global optimum solution and exploits with accuracy. Considering the online optimization of dynamic neural networks (NNs) structured under PSO, Scheffer et al. [26] detected the amount of tool wear for some conventional materials (i.e., $100 \mathrm{Cr} 6$ and $54 \mathrm{CrV} 4$ steel) generated by hard turning. Besides, their algorithms produce details regarding the monitoring system against possible disturbances. Further, the PSO were applied by El-Mounayri et al. [27] to improve the end milling process (i.e., optimize and predict the surface roughness). The GA and NNs were engaged by Ocktem and Erzurumlu [28] to control surface roughness in general milling operation. The TLBO algorithm was applied by Abhishek K et al. [29] to obtain a parametric optimization when machining CFRP composites. A multi-objective TLBO algorithm was developed by $\mathrm{Li}$ et al. [30] to enhance the assembly line containing multiple constraints. A more complex algorithm based on TLBO that incorporated the feedback phase response, structural mutation crossover, and a chaotic perturbation mechanism was embedded in a complex numerical model by Yu et al. [31]. Later on, Chen et al. [32] using an improved algorithm of TLBO and modeling under artificial neural networks obtained a global optimization solution.

Therefore, the PSO and TLBO strategies prove a great success when it is required to tackle complex engineering application derived from experiments with multi-response control. However, only few researches were detected to use PSO and TLBO techniques to enhance the machining process. There is hardly any evidence of optimization of turning parameters for machining of Inconel-800 alloys by combining both meta-heuristic algorithms and MQL condition. For that reason, this assessment proposes a strong investigation of the benefits of using this later combination (optimization through meta-heuristic algorithms using MQL condition) for machining Inconel-800. The outcomes of this work prove the potential of creating a greener and cleaner machining production. Furthermore, a comparison amongst the cooling methods was made to evaluate which method performs best amongst dry, flood, and MQL.

\section{Experimental setup and process strategy}

\subsection{Workpiece materials and cutting inserts}

In this work, the machining process of the nickel-based alloy has been analyzed. The specimens used in the experiments had a total length of $150 \mathrm{~mm}$ and a diameter of $50 \mathrm{~mm}$ from a commercial Inconel-800 (hardness, $\sim 35$ HRC). A spectroscopic analysis was performed to obtain details of material chemical composition. The chemical composition results were inserted in Table 1. The cubic boron nitride inserts with the following characteristics: CCGW 09T304-2, having a positive angle of $7^{\circ}$, with the clearance $80^{\circ}$, rhombic form and a nose radius of $0.4 \mathrm{~mm}$, were engaged in the experiments. During the experiments, the inserts were rigidly mounted in the tool holders that are included in a lathe tool dynamometer.

\subsection{Turning experiments using the MQL strategy}

The turning experiments on the Inconel-800 alloys were performed under a CNC turning lathe machine ("BATLIBOI Sprint 20TC model"). The machine allows varying the spindle speeds between 30 and 4000 RPM whereas it is possible to set the maximum spindle power up to $11 \mathrm{~kW}$. The NOGA make MQL set up was integrated in the actual protocol. To obtain a suitable condition in the machining routine, the water-soluble cutting oil in a ratio 20:1 was introduced. Some parameters were kept constant over entire experiments as follows: the flow rate of $300 \mathrm{ml} / \mathrm{h}$, an air flow rate of $60 \mathrm{l} / \mathrm{min}$, and an imposed pressure of 5 bars. To distribute the cutting fluid, at the interface of the tool-chip, via a hybridized pattern through the nozzles set was used a reciprocating compressor that contains an air-flow rotameter.

\subsection{Measurements}

To produce accurate results, the main characteristics (e.g., flank wear morphology $\left(\mathrm{VB}_{\max }\right)$ and profile of surface roughness $(R a)$ ) generated during this machining routine were evaluated every $30 \mathrm{~s}$. Besides, this parameter has extensive application in industrial field due to its broad tolerability, i.e., more than 50\% usage [33]. Considering the maximum tool life, specified on the ISO 3685 standard, the process was interrupted when $\mathrm{VB}_{\max } \geq 0.60 \mathrm{~mm}$ was reached and the insert was replaced with a new one. The ISO 4287 norm was used as proof guide to evaluate the surface roughness. The optical measurements were made using a Mitutoyo microscope and Mitutoyo SJ 301 surface roughness tester. The cutting force $\left(F_{c}\right)$ was recorded via a TeLC DKM2010 dynamometer connected to the XKM software. The workpiece after machining was investigated in three different points along tool direction movements, hence generating consistent results. The overall contact length, shown in Fig. 1, between tool-chip interface was determined by applying the classical Eq. (1) [34]:

$L=t^{*}\left(2.05^{*} \xi-0.55\right)$

where $\xi=$ coefficient of chip thickness, $t=$ thickness of undeformed chip $=f^{*} \sin \varphi, \xi=\frac{1}{\zeta}=\frac{t}{t_{c}}, f=$ feed rate in millimeters per revolution and $\varphi=$ cutting tool angle in degrees, and $t_{c}=$ end chip thickness in millimeters.

Five different points of measurement were considered for each studied sample to produce statistical relevance. The chip thickness was determined by the average values. Some metallographic specimens were generated from the machined 
Table 1 Chemical composition of Inconel-800

\begin{tabular}{lllllll}
\hline $\mathrm{Ni}$ & $\mathrm{Cr}$ & $\mathrm{Fe}$ & $\mathrm{C}$ & $\mathrm{Al}$ & $\mathrm{Ti}$ & $\mathrm{Al}+\mathrm{Ti}$ \\
\hline $30.0-35.0$ & $19.0-23.0$ & $39.5 \mathrm{~min}$ & $0.10 \mathrm{max}$ & $0.15-0.60$ & $0.15-0.60$ & $0.30-1.20$ \\
\hline
\end{tabular}

surface. The details of the morphological surface were investigated by a scanning electron microscope (SEM, Jeol). The patterns of the worn cutting tool and surface of the chips were considered for microscopy investigation. Figure 2 presents an overview of the entire architecture of the methodology.

\subsection{Machining parameters}

The machining tests were performed simulating three cutting speeds (i.e., 200, 250, and $300 \mathrm{~m} / \mathrm{min}$ ) and generating suitable responses to detect critical machining conditions. The $300 \mathrm{~m} /$ min limit was imposed because of an initial tool damage noted when the cutting speed is over this condition (>300 $\mathrm{m} / \mathrm{min}$ ). Despite this, a lower limit was imposed as regards industrial benefits. According to the state of the art and manufacturing industry, the feed rate was imposed as follows: $0.10,0.15$, and $0.20 \mathrm{~mm} / \mathrm{rev}$. A fixed cut depth of $1 \mathrm{~mm}$ was considered throughout the entire trial protocol.

\subsection{Design of the experiment}

The response surface methodology (RSM) strategy that includes a Box-Behnkens algorithm was applied. Table 2 provides details of the number of turning trials (17) using a CBN cutting tool that allows evaluating the machining parameters and their responses. The methodology was organized as follows: in the first instance, it was to generate a perturbation graph through RSM obtaining the distribution of each

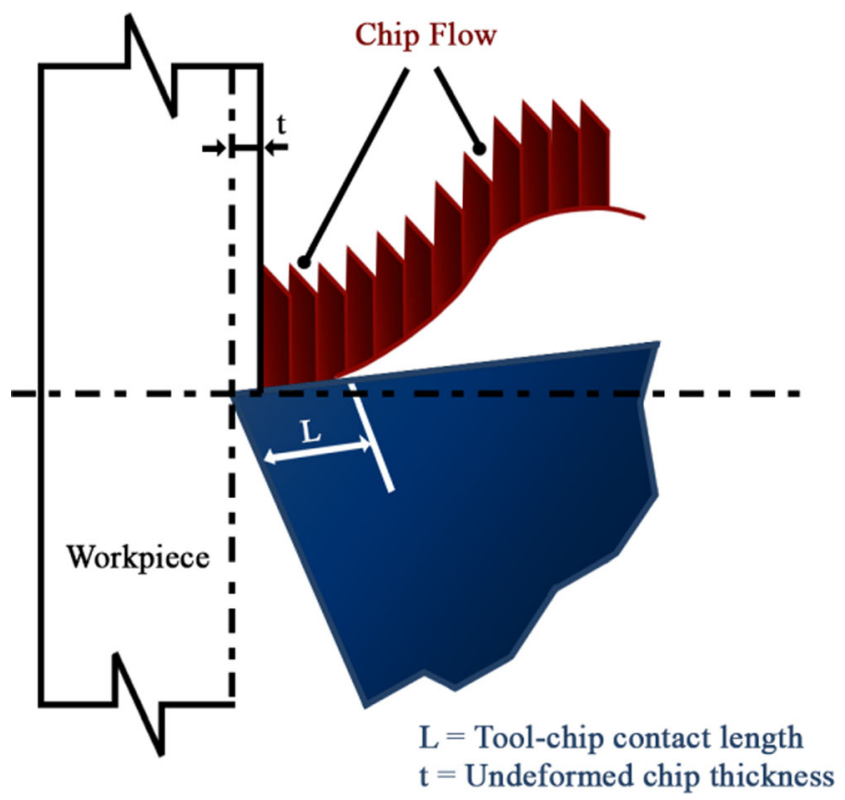

Fig. 1 Schematic diagram of chip-tool contact length parameter on the same specific response. Then, a predictive statistical model was built using ANOVA. Combined objectives from multiple regression analysis were developed, and the results were optimized using PSO, TLBO, and the desirability technique. In the end, the established models were compared and validated against experimental results.

\section{Results and discussions}

The PSO and TLBO algorithms were generated on the MATLAB code. Design-Expert software was used to generate the desirability function model. Table 2 presents data from the experimental protocol and simulated process. In the following subsection is presented an outline of obtained results for each section.

Cutting forces The cutting forces produce major instability on the machine tool equipment that is later transmitted to the workpieces as errors and tolerance violations. The overall variation depends on specific parameters as workpiece material properties, geometry and material of the tool, cutting fluid performances, method of application, and cutting fluid conditions. Applying MQL conditions permits reducing the influence of the cutting force by variation of the feed rate and cutting speed (Fig. 3a). A higher cutting speed generates a potential increase in the cutting temperature which allows a decrease in the cutting forces. Further, once the feed rate is increased, the chip load or the chip area increases that results in high cutting forces. Otherwise, a large approach angle permits as well as decreases the cutting forces. The Inconel-800 superalloy has a low heat transfer coefficient, which during turning progress allows a significant amount of heat to be dispersed on the cutting area causing poor machinability. The dispersed heat is accumulated in the workpiece surface. As such, that generates material softening with some elastic deformation in the subsurface. This later activity (softening and elastic deformation) induces uncontrollable cutting forces.

Surface roughness The guidelines of ISO 4287 standard were used to evaluate the surface roughness values $(R a)$ - taken as averages. It was determined arithmetically from the absolute variance profile as a mean from all "surface valleys" and "peaks" expressed in micrometers. The $R a$ values can vary during turning operation when the cutting speed and feed rate rise (Fig. 3b). Because a higher feed rate is offset on the machined surface by producing wider and higher peaks and valleys, the surface roughness is increased. Likewise, a faster 
Fig. 2 Schematic diagram of experimental setup

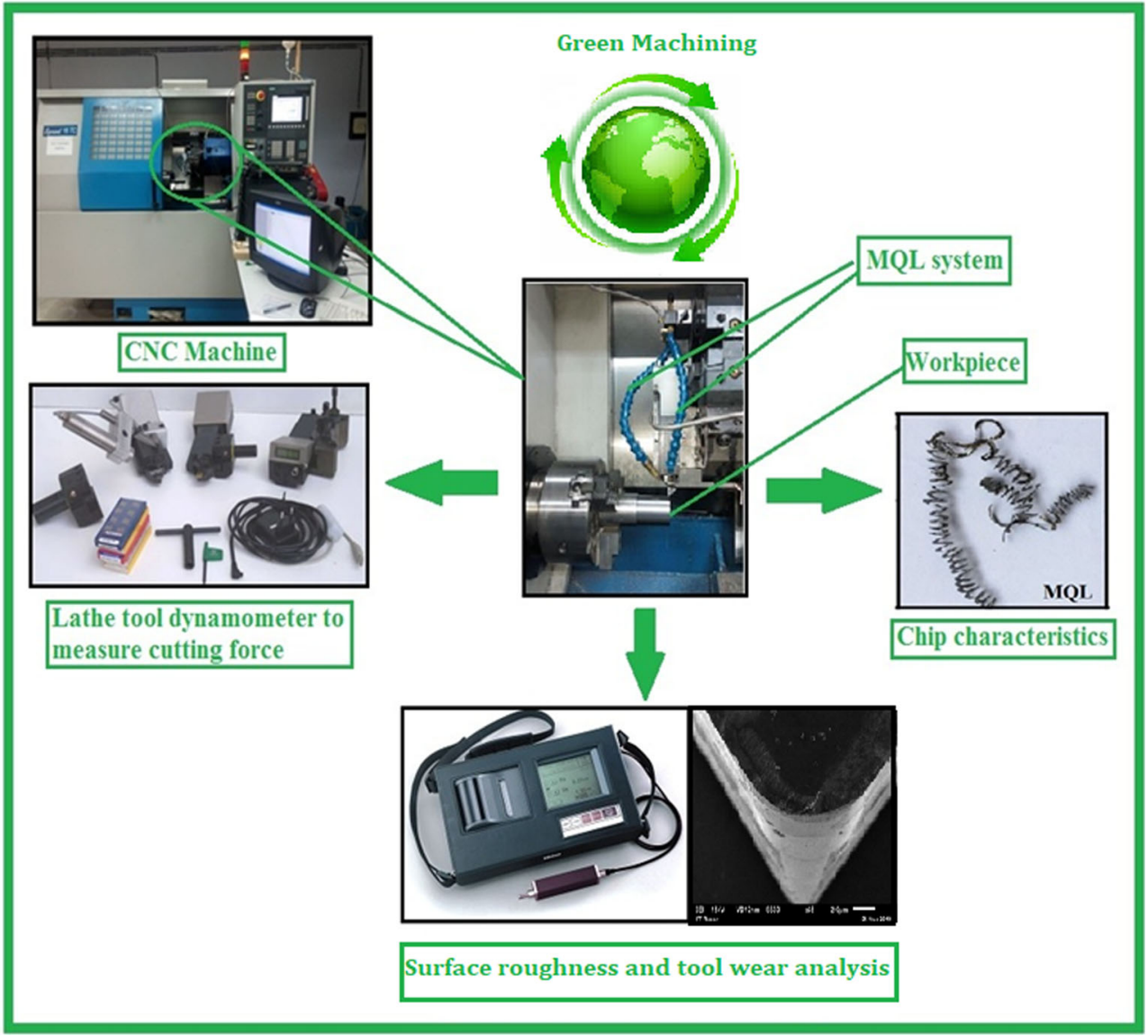

cutting speed may produce some vibrations in the system, provide the harder and tougher nature of Inconel material, and generate a huge amount of local heat. An improvement in the $R a$ profile/values is possible by increasing the cutting
Table 2 Machining parameters with the experimental design and their results

\begin{tabular}{|c|c|c|c|c|c|c|c|c|}
\hline \multirow{2}{*}{$\begin{array}{l}\text { Sr. } \\
\text { no. }\end{array}$} & \multicolumn{3}{|c|}{ Machining parameters } & \multicolumn{4}{|c|}{ Responses } & \multirow[t]{2}{*}{ C.O. } \\
\hline & $v_{c}(\mathrm{~m} / \mathrm{min})$ & $f(\mathrm{~mm} / \mathrm{rev})$ & $\varphi$ deg. $\left(^{\circ}\right)$ & $F_{c}(\mathrm{~N})$ & $R a(\mu \mathrm{m})$ & $V B_{\max }(\mathrm{mm})$ & $L(\mathrm{~mm})$ & \\
\hline 1 & 200 & 0.2 & 75 & 266 & 1.14 & 0.44 & 0.6188 & 1.5468 \\
\hline 2 & 250 & 0.1 & 60 & 192 & 0.89 & 0.30 & 0.5292 & 1.1594 \\
\hline 3 & 250 & 0.1 & 90 & 171 & 0.94 & 0.25 & 0.5817 & 1.1136 \\
\hline 4 & 250 & 0.15 & 75 & 221 & 1.10 & 0.41 & 0.5591 & 1.3976 \\
\hline 5 & 250 & 0.2 & 90 & 244 & 1.21 & 0.48 & 0.6058 & 1.5634 \\
\hline 6 & 250 & 0.15 & 75 & 222 & 1.09 & 0.42 & 0.5548 & 1.4042 \\
\hline 7 & 250 & 0.2 & 60 & 251 & 1.26 & 0.51 & 0.5547 & 1.5957 \\
\hline 8 & 300 & 0.15 & 90 & 210 & 1.19 & 0.46 & 0.5456 & 1.4490 \\
\hline 9 & 250 & 0.15 & 75 & 223 & 1.11 & 0.41 & 0.5591 & 1.4041 \\
\hline 10 & 200 & 0.1 & 75 & 148 & 0.86 & 0.27 & 0.5594 & 1.0587 \\
\hline 11 & 250 & 0.15 & 75 & 220 & 1.10 & 0.42 & 0.5548 & 1.4037 \\
\hline 12 & 200 & 0.15 & 90 & 230 & 0.96 & 0.33 & 0.6180 & 1.3198 \\
\hline 13 & 300 & 0.15 & 60 & 247 & 1.32 & 0.52 & 0.5109 & 1.5955 \\
\hline 14 & 200 & 0.15 & 60 & 238 & 1.00 & 0.32 & 0.5858 & 1.3199 \\
\hline 15 & 250 & 0.15 & 75 & 222 & 1.08 & 0.42 & 0.5548 & 1.4012 \\
\hline 16 & 300 & 0.2 & 75 & 240 & 1.38 & 0.56 & 0.5601 & 1.6654 \\
\hline 17 & 300 & 0.1 & 75 & 144 & 0.83 & 0.39 & 0.5128 & 11,412 \\
\hline
\end{tabular}




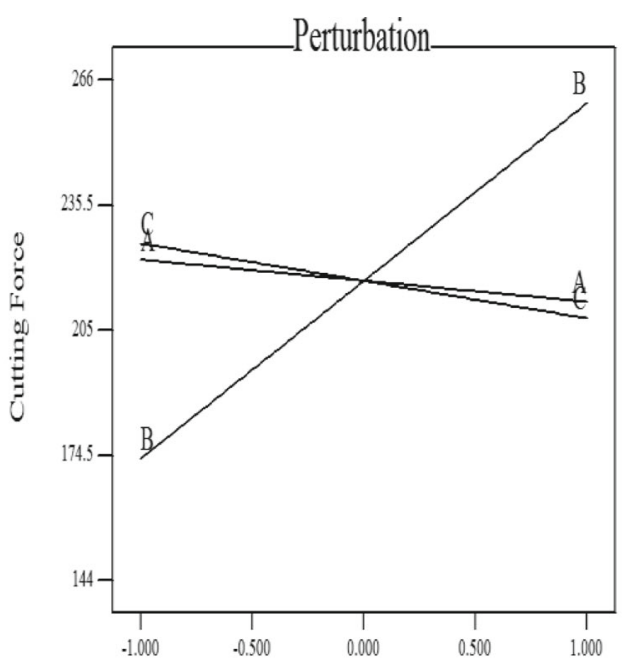

a

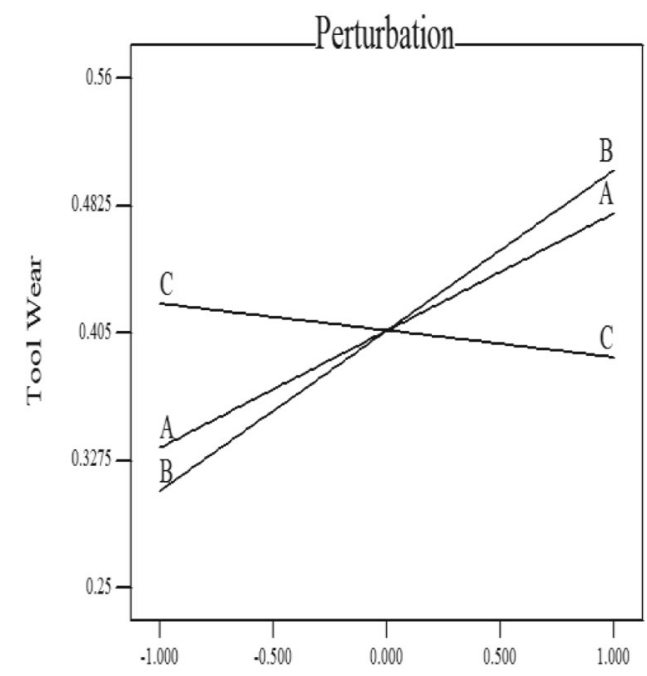

C

Deviation from Reference Point

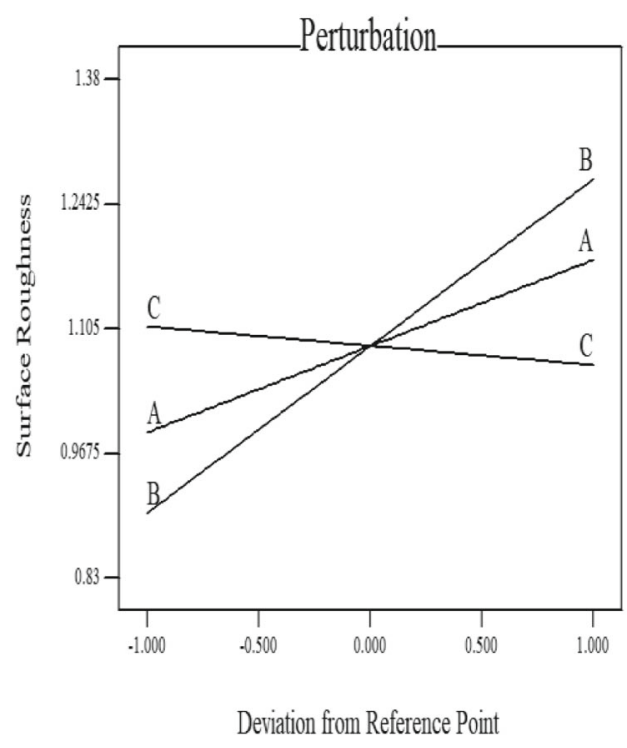

b

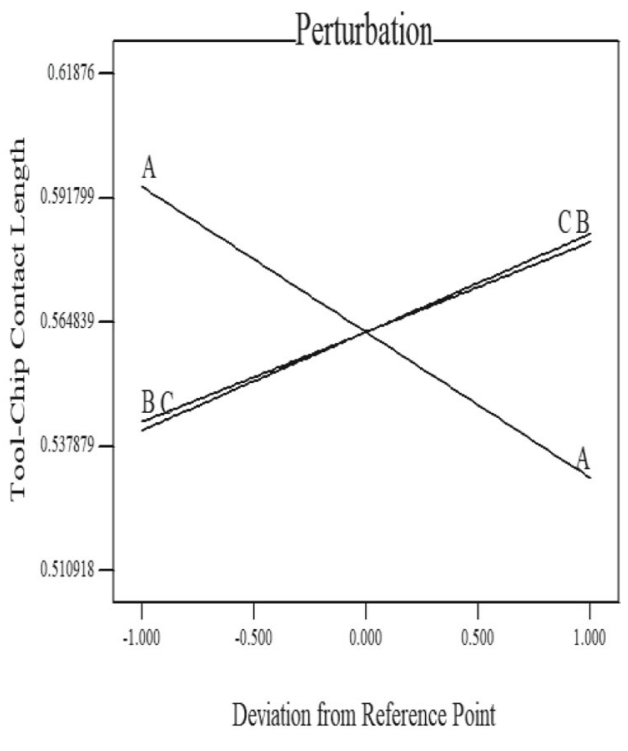

0.15, C: Cutting tool angle $=75.00$

Fig. 3 Effect of process parameters on a cutting forces, $\mathbf{b}$ surface roughness, $\mathbf{c}$ tool wear, $\mathbf{d}$ tool-chip contact length

tool angle. Once this maneuver is embedded, it will be possible to obtain a uniform distribution of the cutting forces and the heat will be spread uniformly on a large portion of the contact area that will produce more evenly $R a$.

Tool wear $\left(\mathrm{VB}_{\max }\right)$ It is well known that the machining process activates heat generation because of hard contact between tool-chip interfaces. This has a major impact on tool life and chip geometry and leads to potentially unpredictable cutting forces. There, the tool damage is stimulated by the adhesion, abrasion, or diffusion mechanisms. However, the influence of the cutting speed and feed rate on tool wear $\left(\mathrm{VB}_{\max }\right)$ is obvious (Fig. $3 \mathrm{c}$ ) and it plays a bigger role in comparison to the cutting tool angle. In fact, the cutting speed and feed rate allow increases in the chip size contact and produces higher friction between its interfaces (of tool-chip), thus simulating more $\mathrm{VB}_{\max }$. The high speed-feed combination could act more detrimental if there is any coating that fails or adhesive bonding progress because it forges the amount of flank wear.

Tool-chip contact length $(L)$ The contact path that forms at the interface of the chip tool permits determining the overall area of contact and becomes essential to understand the region of the heat transfer zone. From experience, the dimension of the tool chip contact varies as a function of cutting speed, feed rate, and cutting tool angle. 
Table 3 ANOVA results for cutting force, surface roughness, tool wear, and tool-chip contact length

\begin{tabular}{lllll}
\hline Factors & \multicolumn{2}{l}{ Responses } & \\
\cline { 2 - 5 } & $F_{c}(\mathrm{~N})$ & $V B_{\max }(\mathrm{mm})$ & $R a(\mu \mathrm{m})$ & $L(\mathrm{~mm})$ \\
\hline$R$-squared & 0.8201 & 0.9488 & 0.8622 & 0.9258 \\
Adj. $R$-squared & 0.7786 & 0.9369 & 0.8304 & 0.9086 \\
Pred. $R$-squared & 0.6289 & 0.8972 & 0.7140 & 0.8575 \\
Adeq. precision & 13.208 & 31.326 & 17.624 & 22.928 \\
Model $F$-value & 19.75 & 80.25 & 27.11 & 54.03 \\
\hline
\end{tabular}

Information about chip details produced during MQL conditions is presented in Fig. 3d. When machining Inconel800 superalloy, it was observed that an increase in the cutting speed generated a reduction of the contact length between the tool and chip. An increase in the cutting speed produces more plastic deformation that becomes even more pronounced because of accumulation of heat on the cutting zone; therefore, shorter tool-chip will occur. Instead, the cutting tool angle and feed rate lead into a longer contact path between the tool and chip. The larger cutting tool angle with the feed rate kept increasing may create a local sliding mode between the tool and chip interface that produces quasi longitudinal grooves at the extremities of the contact area following the chip flow trajectory. Thus, an irregular sliding flow occurs toward a continuous chip that has influence over the tool rake face that generates a long continuous tool-chip contact. The higher feed rates accumulated with more intense cutting speed produce a large portion of chips to plow that further increases the tool-chip contact length.

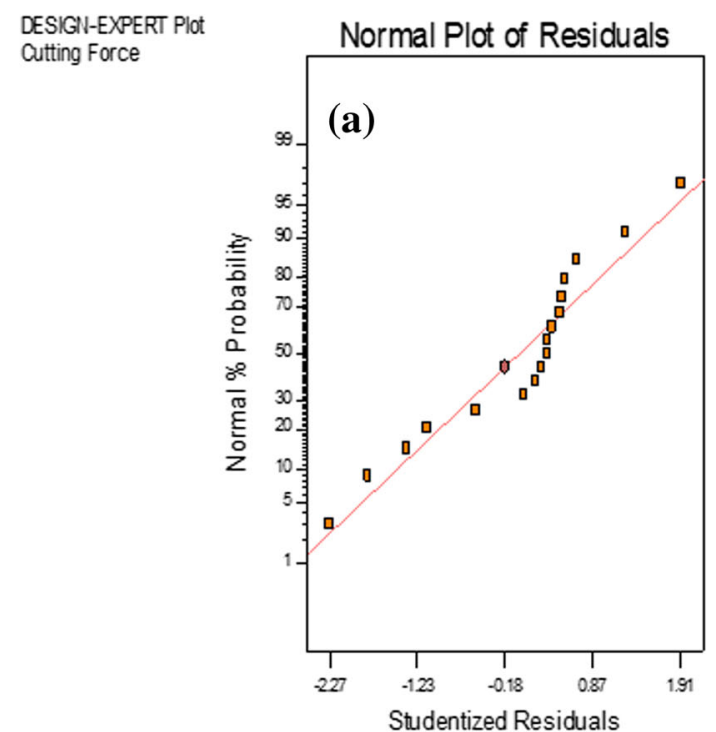

Table 4 Comparison of combined objective values for both materials by PSO, TLBO, and desirability function approach

\begin{tabular}{llllll}
\hline Method & Best & Worst & Average & Avg. time taken & \% success \\
\hline PSO & 1.04998 & 1.06532 & 1.04909 & 8.09 & 90 \\
TLBO & 1.10014 & 1.10865 & 1.10158 & 2.12 & 80 \\
Desirability function & 1.20624 & & & \\
\hline
\end{tabular}

\section{Analysis and optimization}

\subsection{Model robustness}

Table 3 presents data obtained using ANOVA determination in order to prove the validity, in terms of statistical relevance, of employed models. The numerical $R$-squared values are almost equal to 1 while $\operatorname{Adj}-R^{2}$ prediction and Pred- $R^{2}$ seem to fit very well. An adequate precision value over 4 demonstrates its consistency. According to $F$-values, the reported results generated by the regression procedures are statistically valid. Later on, a diagnostic protocol was conducted to check the robustness of our created models. The cutting force (Inconel-800 superalloy) trend was generated through the normal plot distribution (Fig. 4a). Most of the residuals permit building a straight line with minor deviation on the extremities which are found in agreement with experimental determination. Further verification of model robustness was built using residuals versus predicted values (Fig. $4 b)$. The trend was found similar to the normal plot distribution confirming the ANOVA process stability. Other response variables investigated in this survey were simulated under ANOVA, and they indicated the same trend which proves the strategy robustness.
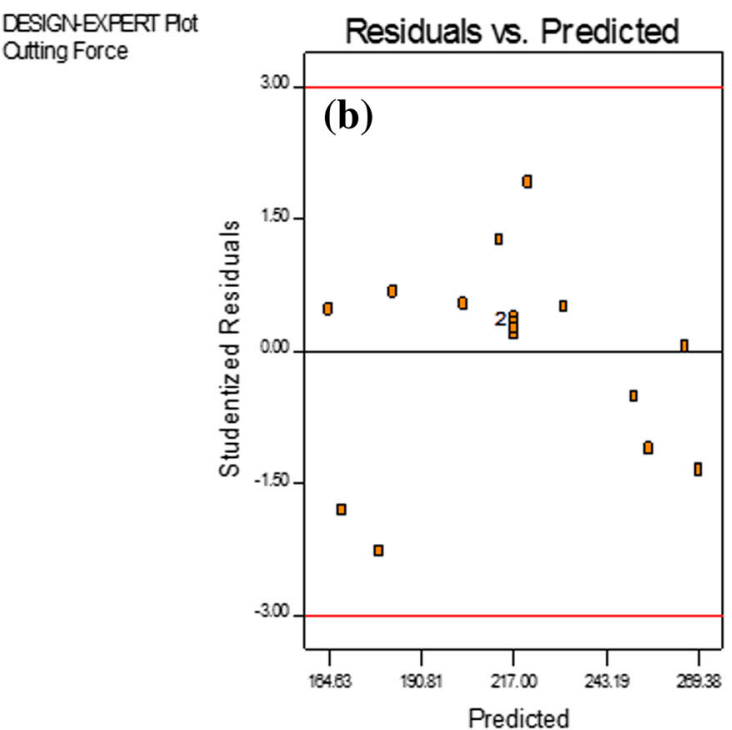

Fig. 4 For cutting forces; a normal plot of residuals, $\mathbf{b}$ plot of residuals vs. predicted 


\subsection{Optimization}

The PSO, TLBO, and desirability analysis were then applied in order to further optimize the input parameters. In the initial stage, a combined target objective was built based on Eq. (2).

$$
\begin{aligned}
\operatorname{Min} \text { C.O. }= & W_{1}{ }^{*}\left(C F / C F_{\min }\right)+W_{2}{ }^{*}\left(S R / S R_{\min }\right) \\
& +W_{3}{ }^{*}\left(T W / T W_{\min }\right)+W_{4}{ }^{*}\left(L / L_{\min }\right)
\end{aligned}
$$

Here, W1, W2, W3, and W4 permit releasing a weight from major responses (i.e., cutting forces (CF), surface roughness (SR), tool wear (TW), and tool-chip contact length $(L)$ ). The sum of their weights is equal to 1 [35]. It is possible to generate as much as possible random combinations to determine the

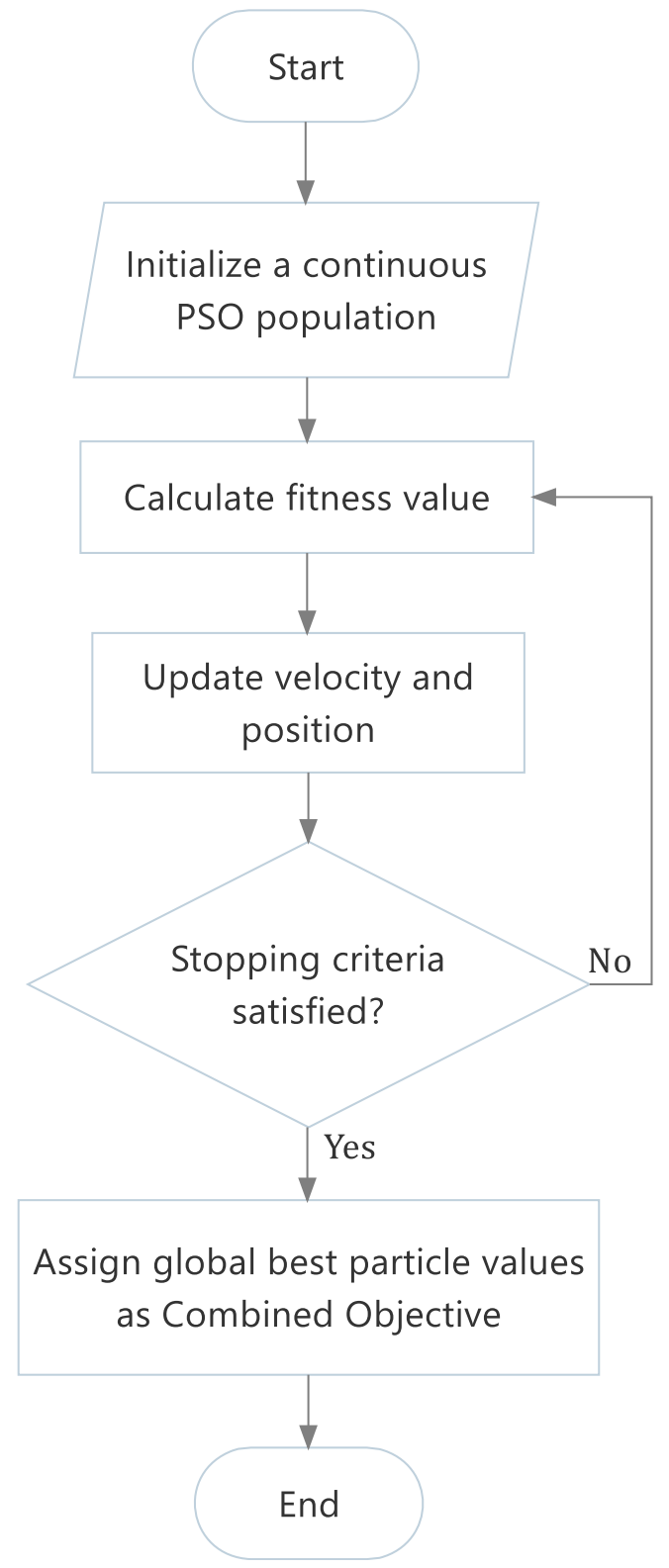

Fig. 5 Flow chart of PSO weightages applied in Eq. 2. Each weight response can vary between 0.1 and 0.5 , generating a final sum equal to 1.0. In this survey, a weightage equal to 0.25 was allocated for every individual target response. A combined objective (C.O.) strategy allows obtaining results that are unique in relation to the individual esteem. It denotes an essential principle of favorable position to use the C.O. strategy.

\subsection{Desirability technique}

The minimal objective values were generated using a desirability technique [36, 37]. It allows identifying an optimum parametric combination from a single or multiple responses generated in the experiment. This technique permits generating a simple solution without any clashing of responses. Besides, it allows varying the input parameters in a large range of variability. The overall advantage when this is used as a combined objective tool is that it allows obtaining the best results. Typically, results generated through the desirability approach are inserted in Table 4.

\subsection{PSO and TLBO}

The regression simulation was conducted in order to detect the fitness function of the optimized models, a function derived from the combined objective. Then, the entire strategy that includes the fitness function incorporated in both meta-heuristics algorithms as was produced using a modern MATLAB code. The boundary conditions were set up from the response minimization. Therefore, the optimum parameters were determined using a general C.O. for both models as shown by Eq. 3 .

$$
\begin{aligned}
\text { C.O. }= & 0.43487+1.51155 E-003^{*} v_{c} \\
& +4.74907^{*} f-1.87380 E-003^{*} \varphi
\end{aligned}
$$

\begin{tabular}{|c|c|}
\hline Parameters & Specification \\
\hline \multicolumn{2}{|l|}{ General parameters } \\
\hline Number of variables & 3 (dimension of search space) \\
\hline Number of particles & 46 \\
\hline Number of iterations & 100 \\
\hline Inertia weight, $W$ & 0.7 \\
\hline \multicolumn{2}{|l|}{ Learning Rate } \\
\hline $\mathrm{C} 1 \mathrm{max}=\mathrm{C} 2 \mathrm{max}$ & 1.7 \\
\hline $\mathrm{C} 1 \mathrm{~min}=\mathrm{C} 2 \mathrm{~min}$ & 0.5 \\
\hline $\mathrm{C} 1=\mathrm{C} 2=\mathrm{Cmin}+R^{*}(\mathrm{Cmax}-\mathrm{Cmin})$ & $\begin{array}{l}\text { Where } R=\text { Current } \\
\quad \text { iterations/Total iterations }\end{array}$ \\
\hline$X_{\min }$ & {$\left[\begin{array}{lll}200 & 0.1 & 60\end{array}\right]$} \\
\hline$X_{\max }$ & {$\left[\begin{array}{lll}300 & 0.2 & 90\end{array}\right]$} \\
\hline
\end{tabular}

Table 5 Parameters of PSO 
PSO The speed of cutting $\left(v_{c}\right)$, value of feed rate $(f)$, and opening of the cutting tool angle $(\varphi)$ are considered as the particles on the PSO simulation. The PSO algorithm is structured as

First step: parameter bounds: The particle values (i.e., $v_{c}$, $f, \varphi$ ) need to be generated randomly from the value ranges (i.e., from minimum to maximum) which are expressed by following Eqs. (4) to (6).

$200 \leq v_{c} \leq 300$

$0.10 \leq f \leq 0.20$

$60 \leq \varphi \leq 90$

Second step: The speed of particles was selected randomly from the value ranges (i.e., starting with minimum to maximum) of the particle values (i.e., $v_{c}, f, \varphi$ ).

Third step: An objective function value for each "particle" investigated was determined, then the pbest and gbest were allocated.

Fourth step: A new objective function value was determined for the updated particle positions. Consequently, a novel and better pbest and gbest were identified.

Fifth step: The iterations are repeated until the best convergence is obtained.

Figure 5 summarizes the PSO within a flow process chart. Details of the projected algorithm are inserted in Table 5.

TLBO Equation 3 described for C.O. was used in TLBO algorithm for parametric optimization. The boundary conditions for the parameters are collected from the Eqs. (4) to (6). The optimum values that permit controlling the main common parameters (i.e., population size and iteration numbers) were simulated for various number of time and using different population sizes until the convergence was determined. The identified solution was based on the teaching/learning approach. The potential multiple solutions were removed and updated randomly. The entire numbers of function evaluated as described as $\{(2 *$ size of population * iterations number) + (function target to activate the removal of duplication)\}. This pseudo-formula permits counting the entire number of evaluations during TLBO execution. However, it is difficult to detect with accuracy when duplication occurs. For robustness, the experiments were run using different population sizes and 1000 function evaluation to obtain the best convergence. Figure 6 shows the flow chart for TLBO. Figure 7 presents details of the convergence characteristics chart of the TLBO and PSO models.

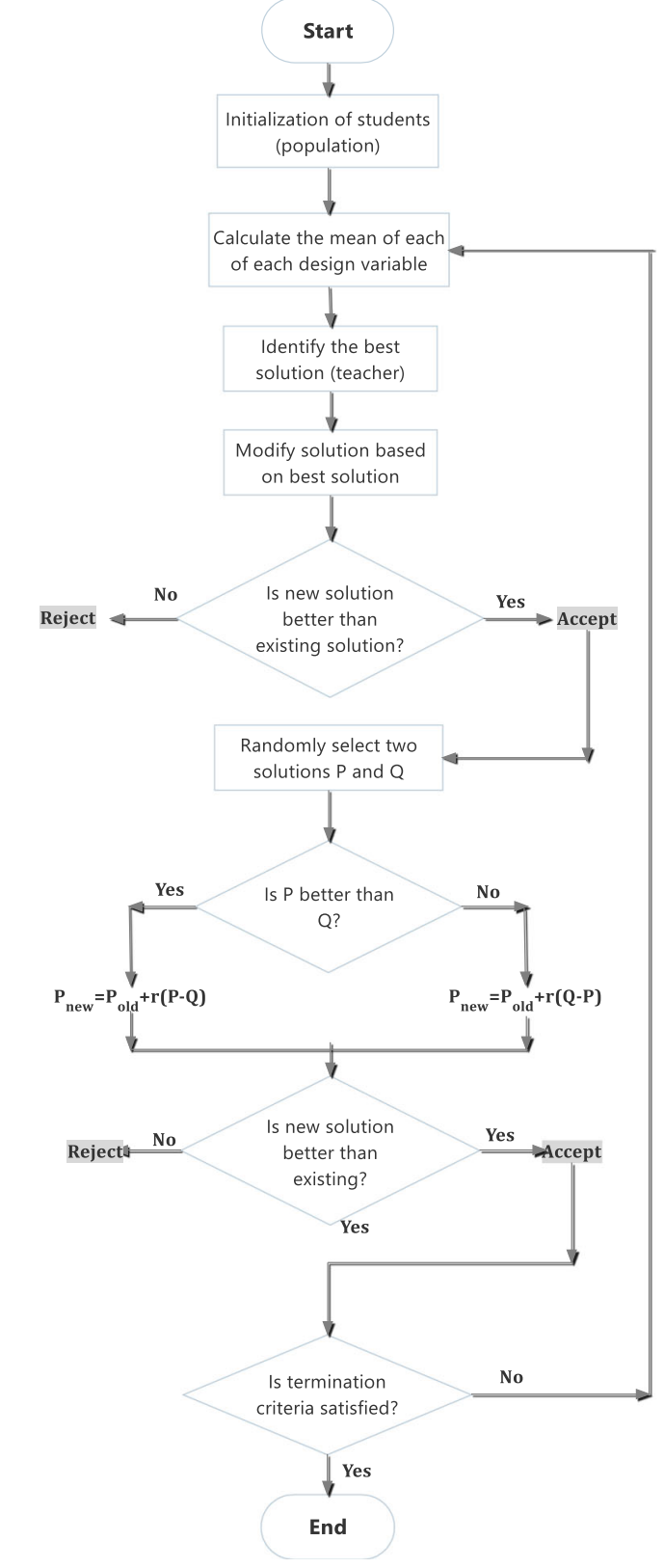

Fig. 6 Flow chart of TLBO

A summary of optimal results generated from investigated techniques, together with the most important values of C.O. (i.e., the best, worst, and its average values), is present in Table 4 . The high percentage of accuracy combined with an optimal time of simulation was detected after 100 runs. The PSO demonstrated a better rate of success (90\%) compared to TLBO that achieved only $80 \%$. It is due to a search space that is guided by the pbest and gbest values. However, the PSO requires $8.09 \mathrm{~s}$ to achieve the global optimal value while the TLBO needs only $2.12 \mathrm{~s}$, respectively. The freedom of algorithm-specific parameters (i.e., no need of a defined algorithm parameter for execution) implies less time, thus permitting faster convergence in respect to PSO (details on Fig. 7). An experimental validation was 
Fig. 7 Convergence characteristics of PSO and TLBO

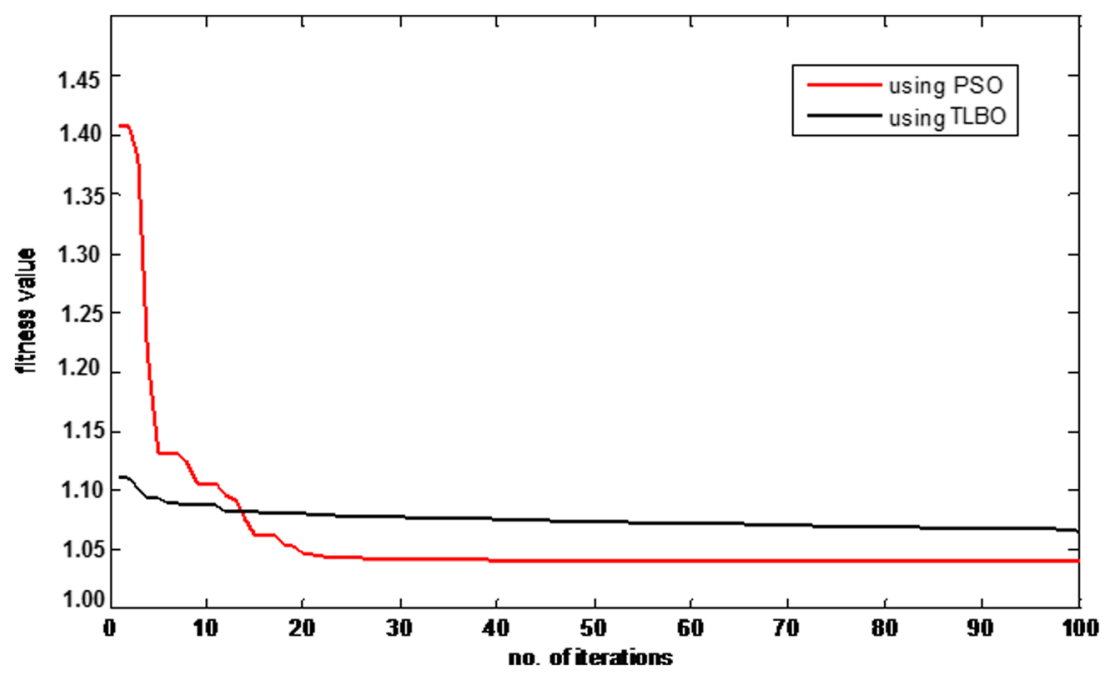

produced for the results obtained in the optimization process. It is worth noticing that the values generated through optimization models (i.e., PSO or TLBO) prove higher accuracy in comparison to the one obtained from desirability function approach (Table 6). Therefore, the efficiency of using optimization was demonstrated through the meta-heuristic algorithms (i.e., PSO and TLBO) in order to improve the machining characteristics of some specific Inconel-800 superalloy produced with the MQL conditions.

\section{Evaluation of machinability during dry, wet, and MQL strategy}

The four main responses (i.e., cutting forces values, amount of tool wear, profile of surface roughness, and the contact length of tool-chip) were identified to indicate the overall machinability while machining Inconel-800 superalloy using MQL, dry, and wet strategy, respectively. First, the performance of the cutting force is compared and shown in Fig. 8. The $x$-axis of this figure is showing the values of the cutting parameters as in order. For instance, the 200/0.2/75 stands for speed $(\mathrm{m} / \mathrm{min}) /$ feed $(\mathrm{mm} / \mathrm{rev}) /$ cutting tool angle $\left(^{\circ}\right)$, respectively. In other words, the cutting speed is $200 \mathrm{~m} / \mathrm{min}$, the feed rate is $0.2 \mathrm{~mm} / \mathrm{rev}$, and the approach angle of the cutting tool is $75^{\circ}$. The performance found for machining on dry and/or wet machining conditions projects slightly higher cutting force values

Table 6 Optimal parameter settings

\begin{tabular}{lllll}
\hline Parameters & $v_{c}(\mathrm{~m} / \mathrm{min})$ & $f(\mathrm{~mm} / \mathrm{rev})$ & $\varphi$ deg. $\left(^{\circ}\right)$ & C.O. \\
\hline PSO & 215 & 0.10 & 82 & 1.04909 \\
TLBO & 215 & 0.10 & 82 & 1.10158 \\
Desirability & 215 & 0.10 & 82 & 1.20624 \\
Experimental & 215 & 0.10 & 82 & 1.03486 \\
\hline
\end{tabular}

in respect to MQL technology (Fig. 8). This is because the lubrication condition created within the MQL becomes better on the cutting zone whereas the tool generates a "perfect" contact with the workpiece. They reduce the sticking mechanism and induce a meaningful shear process. Besides, there the friction is reduced because by using the MQL system the coolant is properly distributed, in the cutting area, achieving a boundary lubrication condition. Patterns of tool wear and the cutting inserts after processing the Inconel-800 superalloy under MQL, dry, and wet conditions are presented in Fig. 9. The rake faces reveal deep craters caused by the temperature/ friction variation when machining by dry and/or wet machining and significant fracture patterns on the cutting edge (Fig. 9). The size of crater patterns generated during MQL is much smaller compared to dry and/or wet machining due to proper lubrication. Further, the MQL lubrication allows decreasing the quantity of the flank wear.

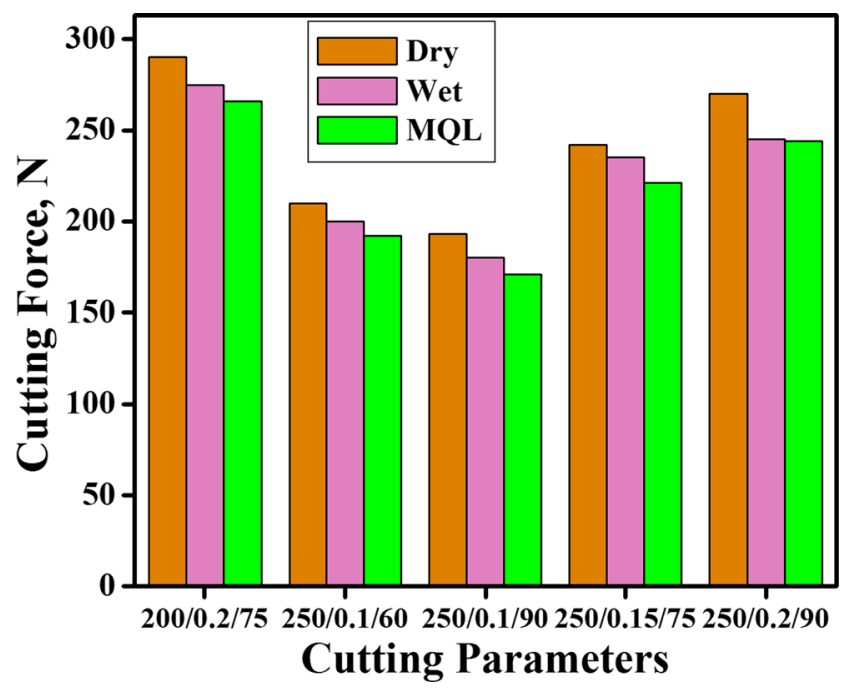

Speed (m/min)/Feed (mm/rev)/Cutting tool angle $\left(^{\circ}\right)$

Fig. 8 Cutting forces under dry, wet, and MQL conditions 
Fig. 9 SEM of tool surface while machining Inconel-800 alloy at $v_{c}=300 \mathrm{~m} / \mathrm{min}, f=0.2 \mathrm{~mm} / \mathrm{rev}$, and $\varphi=75^{\circ}$. a Dry, b wet, $\mathbf{c}$ MQL

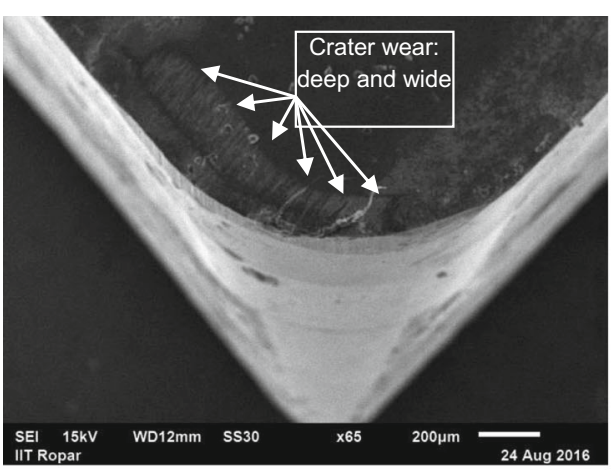

(a)

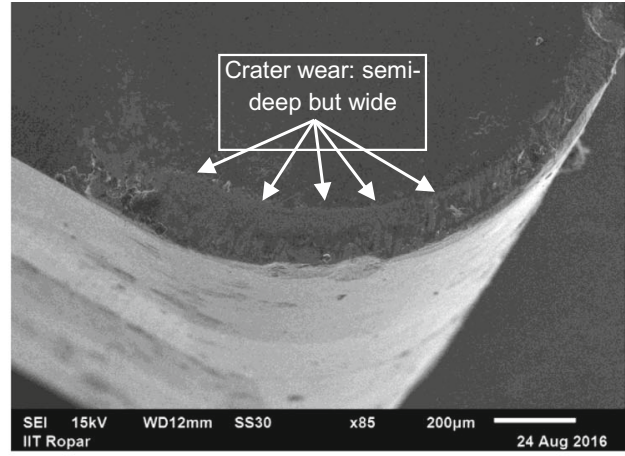

(b)

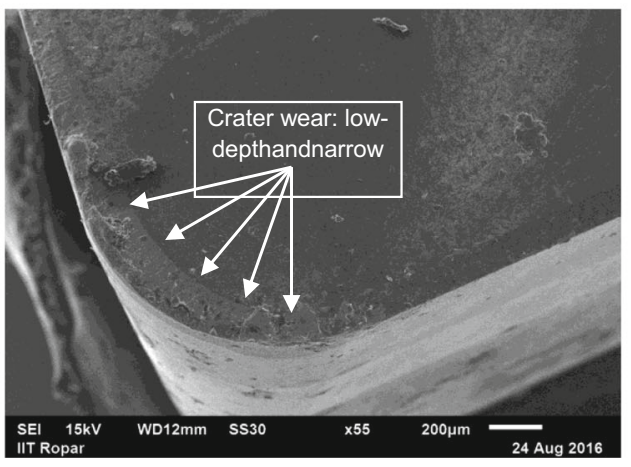

(c)

The process capabilities were investigated as well as in terms of surface roughness profile (Fig. 10) to obtain quantitative information. Here, the $x$-axis is showing the values of the cutting parameters as in order. For instance, the 200/0.2/75 stands for speed $(\mathrm{m} / \mathrm{min}) /$ feed $(\mathrm{mm} / \mathrm{rev}) /$ cutting tool angle $\left({ }^{\circ}\right)$, respectively. In other words, the cutting speed is $200 \mathrm{~m} / \mathrm{min}$, the feed rate is $0.2 \mathrm{~mm} / \mathrm{rev}$, and the approach angle of the cutting tool is $75^{\circ}$. Further qualitative evaluation was detected from the

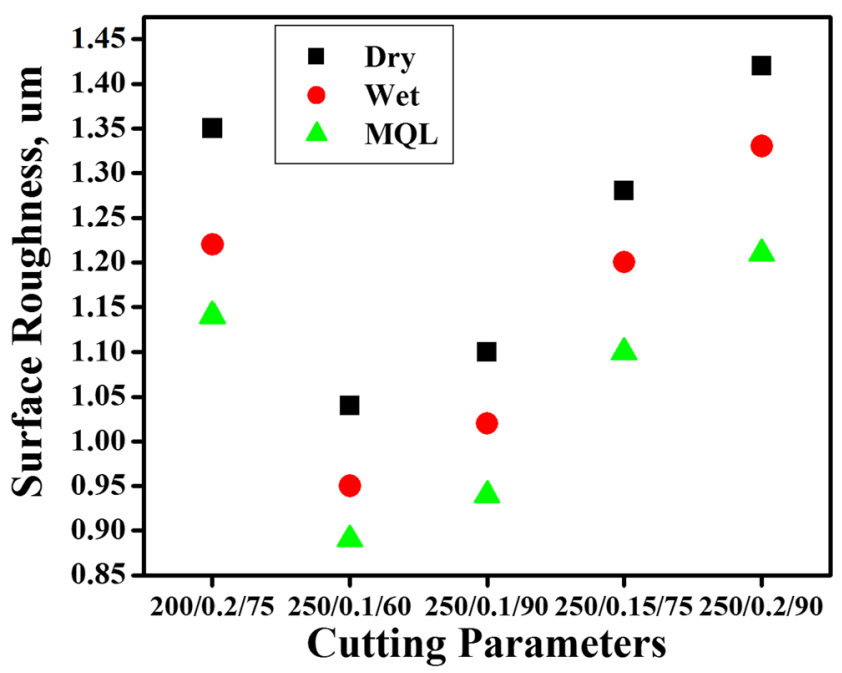

Speed $(\mathrm{m} / \mathrm{min}) /$ Feed $(\mathrm{mm} / \mathrm{rev}) / \mathrm{Cutting}$ tool angle $\left(^{\circ}\right)$

Fig. 10 Surface roughness values under dry, wet, and MQL conditions optical micrographs performing SEM analysis (Fig. 11). The surface conditions are closely related to the performances of the cooling strategy. A higher surface profile is generated by dry and wet machining when comparing to MQL. Further, the MQL provides reduced chip length formation while the chips break into smaller parts generating a minimum rubbing contact. As a result, the surface roughness is reduced in MQL-assisted machining. Further, the surfaces machined under MQL conditions do not contain any cavities or metal debris. Details of the contact path between the tool and chip are presented in Fig. 12. Here, the $x$-axis is showing the values of the cutting parameters as in order. For instance, the 200/0.2/75 stands for speed $(\mathrm{m} / \mathrm{min}) /$ feed $(\mathrm{mm} / \mathrm{rev}) /$ cutting tool angle $\left(^{\circ}\right)$, respectively. As such, the cutting speed is $200 \mathrm{~m} / \mathrm{min}$, the feed rate is $0.2 \mathrm{~mm} /$ rev, and the approach angle of the cutting tool is $75^{\circ}$. It reveals the potential of the MQL strategy to reduce the tool-chip contact length over the other two methods investigated in this survey. In fact, a reason of this phenomenon is that the chips are broken when MQL-induced static pressure is in action. Presumably, such static pressure is not typical for dry and wet machining. The chip breakage produced during dry and wet strategy comes from hard contact between the chip parts and a potential obstructer that is generated in a shear plane fracture cause of negative bending moment. Therefore, the chips' breakability generated during MQL is formed as a short helical spring-like structure (Fig. 13). Further, the blue colors of the chips from the dry and wet strategy reveal potential generation 
Fig. 11 SEM micrographs of machined surfaces at $v_{c}=300 \mathrm{~m} /$ $\min , f=0.2 \mathrm{~mm} / \mathrm{rev}$, and $\varphi=75^{\circ}$. a Dry, b wet, $\mathbf{c} \mathrm{MQL}$ (a)

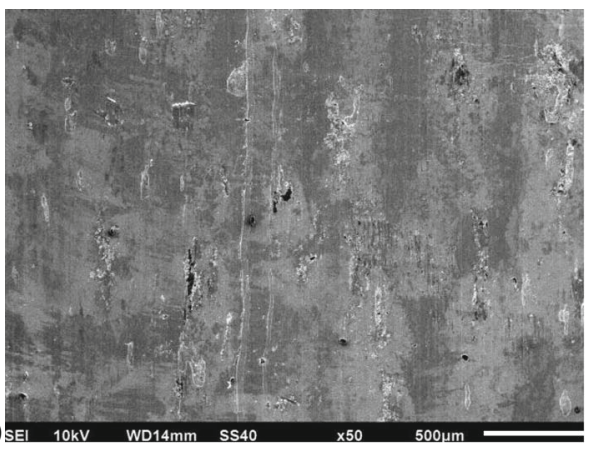

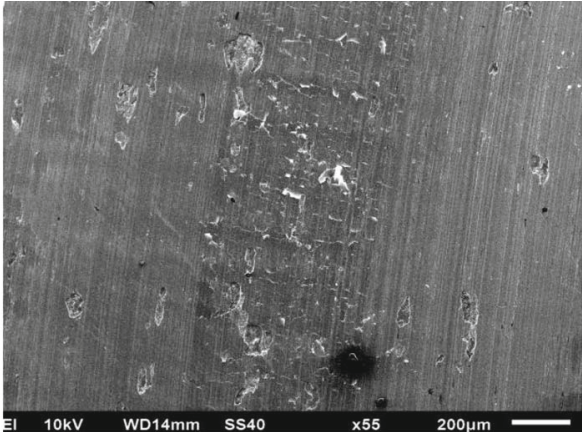

(c)

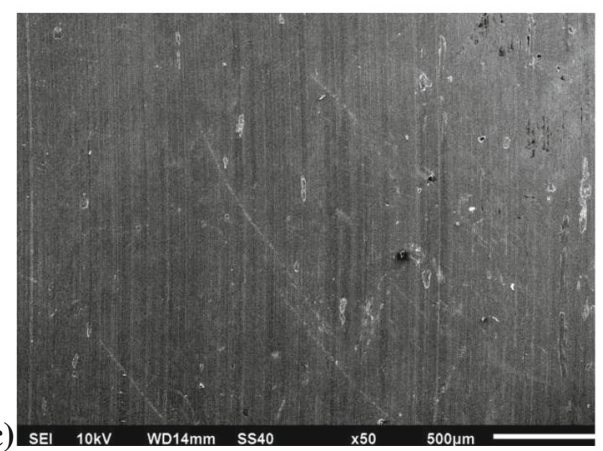

of high temperature near the deformation zone. In contrast, a light golden color was identified on the chips created by MQL, which indicates a less temperature on the interface of contacted parts (tool/chip). The surfaces of rake parts were analyzed by SEM after machining with all three processes used in this survey. Figure 14 shows that a more refined chip morphology is attained in the MQL condition. Such refinement includes evenand-regular chip edges. On the other side, typical chips for dry and wet conditions revealed harsh edges with asymmetrical dimensions, uneven distribution of material, and irregular saw-teeth profile chips.

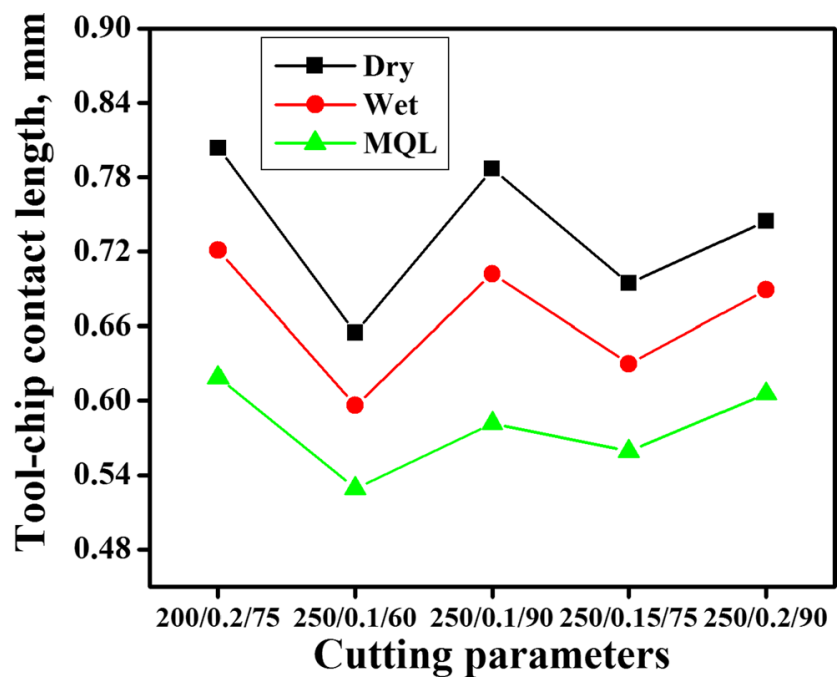

Speed $(\mathrm{m} / \mathrm{min}) /$ Feed $(\mathrm{mm} / \mathrm{rev}) /$ Cutting tool angle $\left({ }^{\circ}\right)$

Fig. 12 Tool-chip contact length values obtained under dry, wet, and MQL conditions

\section{Summary}

The results gathered in this work and from previous published work were presented and debated. The following segments provide these details.

\subsection{Literature's approaches}

- Kamata and Obikawa [14] performed experimental turning research on Inconel-718 alloy by considering processes under conventional dry, wet, and/or minimal quantity lubrication (MQL).

- Tazehkandi et al. [11] proposed a solution to eliminate the cutting fluids on machining Inconel-725 by using an innovative coating tool.

- Pusavec et al. $[15,16]$ introduced the coated carbide tool for better machining/turning of Inconel-718 alloy on dry, wet, and minimum cutting fluid methods.

- Likewise, Tazehkandi et al. [17] used spray strategy on eco-friendly vegetable oil as lubricant and MQL within turning of Inconel-706 (considered a very hard-tomachine material).

- Scheffer et al. [26] proposed an online optimization technique based on dynamic neural network (NNs) approach to reduce the tool wear while simulated the hard turning of $100 \mathrm{Cr} 6$ and $54 \mathrm{CrV} 4$ steel.

- El-Mounayri [27] applying PSO optimization technique generated an improvement in the surface roughness produced by end milling routine. 
Fig. 13 Chip samples obtained under dry, wet, and MQL

conditions at $v_{c}=300 \mathrm{~m} / \mathrm{min}, f=$

$0.2 \mathrm{~mm} / \mathrm{rev}$, and $\varphi=75^{\circ}$

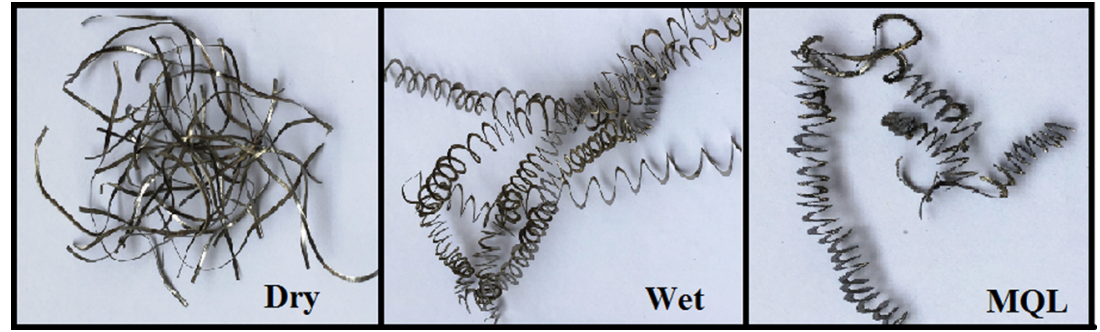

- Ocktem and Erzurumlu [28] combining neural network techniques and genetic algorithms detected the optimum surface profile for some milling operation.

- Abhishek K et al. [29] embedded a TLBO algorithm to obtain a parametric evaluation that permits optimizing the turning processes for CFRP composites when it is used a single point cutting tool.

- Li et al. [30] introduced a multi-objective TLBO algorithm to generate a balance for a two-sided line assembly that contains multiple constraints.

- Yu et al. [31] used a complex TLBO algorithm based on feedback phase, mutation crossover operation, and chaotic perturbation activity to provide a solution for complex numerical and engineering challenges.
- Chen et al. [32] considered artificial neural networks and some global optimization techniques on the TLBO algorithm that contain a variable population scheme.

\subsection{Model robustness over literature's approaches}

- In this paper, the Box-Behnkens response surface methodology (RSM) design was favored because for each variable only three levels are sufficient to provide fruitful results in the simplest manner. Moreover, the least tendency to corruption such as those caused by the experimental setup and operation are attained. As such, economic
Fig. 14 SEM of chips at $v_{c}=$ $300 \mathrm{~m} / \mathrm{min}, f=0.2 \mathrm{~mm} / \mathrm{rev}$, and $\varphi=75^{\circ}$. a Dry, b wet, $\mathbf{c}$ MQL

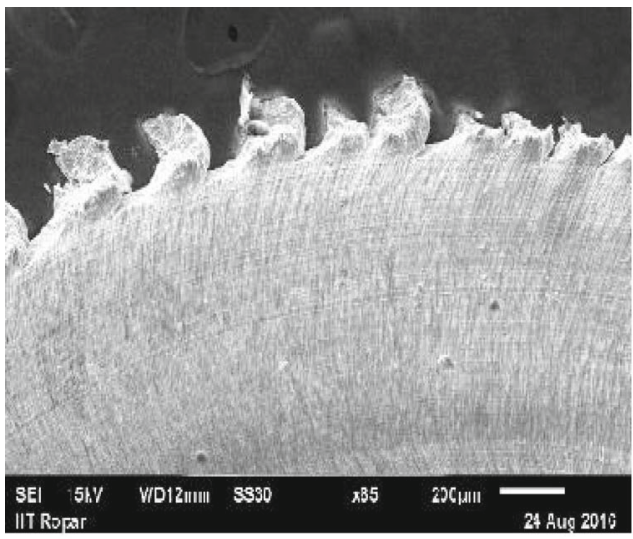

(a)

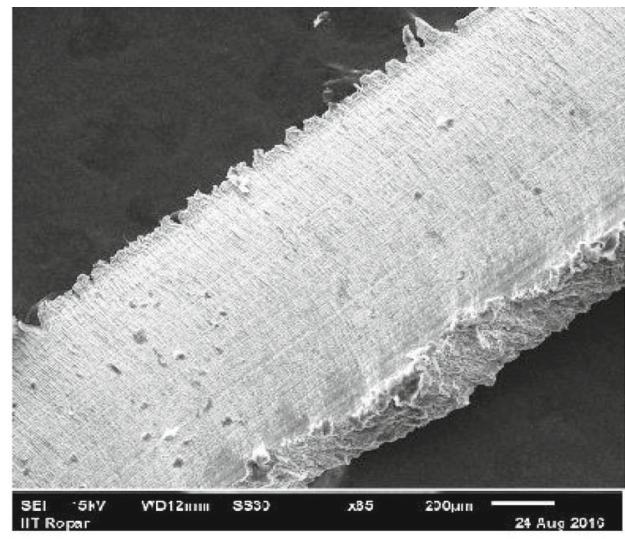

(b)

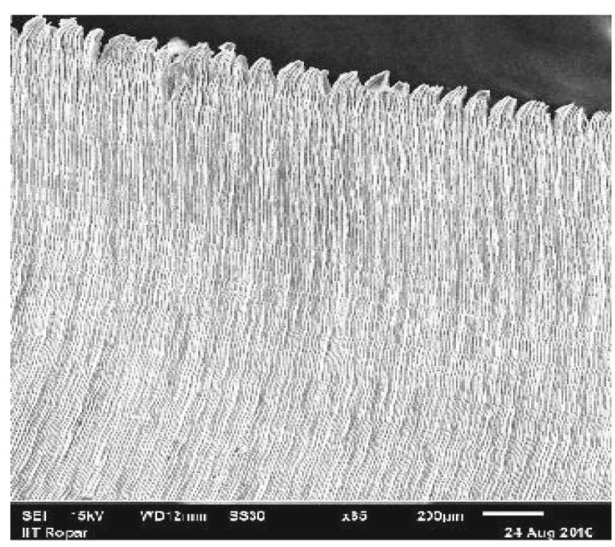

(c) 
benefits are achieved due to the reduction of the number of total experiments - attainment of commercial advantage.

- The literature review shows lack of data in terms of turning of Inconel-800 superalloy using different solutions as dry, wet, and MQL strategy.

- In addition, it was noted that no research regarding process optimization using meta-heuristic algorithms for turning parameters of Inconel-800 and that too when MQL plays along, respectively.

- In that respect, the proposed research brings a quite unique strategy considering an advanced optimization technique along an MQL condition to better turning of Inconel-800 in a sustainable production manner.

\section{Conclusions}

The turning experiments were conducted on difficult-to-cut nickel-based superalloy such as Inconel-800 considering various cutting conditions. The experimental work together with the optimization algorithms permits a better control of different input variables (three cutting speed levels, together with different feed rates and variation of the cutting tool angle) and generating the following conclusions:

1. The performance of meta-heuristic algorithms implemented (i.e., PSO and TLBO) here operates in a better manner in respect to the traditional desirability function approach. Therefore, the meta-heuristic algorithms prove to have a great potential in the detection of the best machining parameters for improved machinability of Inconel-800 superalloy considering the MQL condition.

2. When comparing the cooling conditions, the cooling strategy of deploying minimum quantity cutting fluid has been found beneficial for machining difficult-to-machine nickel-based superalloy such as Inconel-800. It helps to reduce the cutting forces, tool wear, surface roughness, and tool-chip contact length while turning the Inconel800 superalloy.

3. The decrease in the cutting forces during MQL machining occurs once the cutting speed and cutting tool angle are raised and the feed rate is reduced. Nonetheless, when the cutting speed and feed rate raised were detected that an increased amount of tool wear and surface morphology in terms of roughness growth. The contact length between tool and chip diminishes when the cutting speed is high while a bigger feed rate along with a larger approach angle generates a large chip-tool contact area.

4. The validity/relevance of ANOVA simulation was determined by a high coefficient (e.g., 0.9). Thus, the model used is capable of predicting the responses with high accuracy for the proposed machining parameters range.
5. When machining Inconel-800 superalloy, by turning using MQL conditions, it is necessary to employ a parametric setting as the cutting speed $\sim 215 \mathrm{~m} / \mathrm{min}$ and feed rate $\sim 0.10 \mathrm{~mm} / \mathrm{rev}$ along with a cutting tool angle $\sim 82^{\circ}$ to generate superior quality in terms of $F_{c}, R a, \mathrm{VB}_{\max }$, and $L$. By applying the later condition, it will be possible to obtain an economic and ecological process of advantage.

Acknowledgements Authors are grateful to the NIT Hamirpur, India for providing the experimental facilities.

Open Access This article is distributed under the terms of the Creative Commons Attribution 4.0 International License (http:// creativecommons.org/licenses/by/4.0/), which permits unrestricted use, distribution, and reproduction in any medium, provided you give appropriate credit to the original author(s) and the source, provide a link to the Creative Commons license, and indicate if changes were made.

Publisher's note Springer Nature remains neutral with regard to jurisdictional claims in published maps and institutional affiliations.

\section{References}

1. Gupta M, Pruncu C, Mia M, Singh G, Singh S, Prakash C, Sood P, Gill H (2018) Machinability investigations of Inconel-800 super alloy under sustainable cooling conditions. Materials (Basel) 11: 2088. https://doi.org/10.3390/ma11112088

2. Mia M, Dhar NR (2018) Effects of duplex jets high-pressure coolant on machining temperature and machinability of Ti-6Al-4V superalloy. J Mater Process Technol 252:688-696. https://doi.org/10. 1016/j.jmatprotec.2017.10.040

3. Ma J-W, Wang F-J, Jia Z-Y, Gao Y-Y (2016) Machining parameter optimization in high-speed milling for Inconel 718 curved surface. Mater Manuf Process 31:1692-1699. https://doi.org/10.1080/ 10426914.2015.1117623

4. Gupta MK, Sood PK (2017) Machining comparison of aerospace materials considering minimum quantity cutting fluid: a clean and green approach. Proc Inst Mech Eng C J Mech Eng Sci 231:14451464. https://doi.org/10.1177/0954406216684158

5. Sharma VS, Dogra M, Suri NM (2009) Cooling techniques for improved productivity in turning. Int J Mach Tools Manuf 49: 435-453. https://doi.org/10.1016/j.ijmachtools.2008.12.010

6. Sharma J, Sidhu BS (2014) Investigation of effects of dry and near dry machining on AISI D2 steel using vegetable oil. J Clean Prod 66:619-623. https://doi.org/10.1016/j.jclepro.2013.11.042

7. Mulyadi IH, Balogun VA, Mativenga PT (2015) Environmental performance evaluation of different cutting environments when milling H13 tool steel. J Clean Prod 108:110-120. https://doi.org/ 10.1016/j.jclepro.2015.07.024

8. Gupta MK, Sood PK, Singh G, Sharma VS (2017) Sustainable machining of aerospace material - Ti (grade-2) alloy: modeling and optimization. J Clean Prod 147:614-627. https://doi.org/10. 1016/j.jclepro.2017.01.133

9. Singh G, Gupta MK, Mia M, Sharma VS (2018) Modeling and optimization of tool wear in MQL-assisted milling of Inconel 718 superalloy using evolutionary techniques. Int J Adv Manuf Technol 97:481-494. https://doi.org/10.1007/s00170-018-1911-3

10. Mia M, Dhar NR (2017) Influence of single and dual cryogenic jets on machinability characteristics in turning of Ti-6Al-4V. Proc Inst 
Mech Eng B J Eng Manuf 0954405417737581:711-726. https:// doi.org/10.1177/0954405417737581

11. Hosseini Tazehkandi A, Pilehvarian F, Davoodi B (2014) Experimental investigation on removing cutting fluid from turning of Inconel 725 with coated carbide tools. J Clean Prod 80:271-281. https://doi.org/10.1016/j.jclepro.2014.05.098

12. Boswell B, Islam MN, Davies IJ, Ginting YR, Ong AK (2017) A review identifying the effectiveness of minimum quantity lubrication (MQL) during conventional machining. Int J Adv Manuf Technol 92:321-340. https://doi.org/10.1007/s00170-017-0142-3

13. Khettabi R, Nouioua M, Djebara A, Songmene V (2017) Effect of MQL and dry processes on the particle emission and part quality during milling of aluminum alloys. Int J Adv Manuf Technol 92: 2593-2598. https://doi.org/10.1007/s00170-017-0339-5

14. Kamata Y, Obikawa T (2007) High speed MQL finish-turning of Inconel 718 with different coated tools. J Mater Process Technol 192-193:281-286. https://doi.org/10.1016/j.jmatprotec.2007.04. 052

15. Pusavec F, Deshpande A, Yang S, M'Saoubi R, Kopac J, Dillon OW Jr, Jawahir IS (2014) Sustainable machining of high temperature nickel alloy - Inconel 718: part 1 - predictive performance models. J Clean Prod 81:255-269. https://doi.org/10.1016/j. jclepro.2014.06.040

16. Pusavec F, Deshpande A, Yang S, M'Saoubi R, Kopac J, Dillon OW Jr, Jawahir IS (2015) Sustainable machining of high temperature nickel alloy-Inconel 718: part 2-chip breakability and optimization. J Clean Prod 87:941-952

17. Hosseini Tazehkandi A, Shabgard M, Pilehvarian F (2015) On the feasibility of a reduction in cutting fluid consumption via spray of biodegradable vegetable oil with compressed air in machining Inconel 706. J Clean Prod 104:422-435. https://doi.org/10.1016/j. jclepro.2015.05.039

18. Mia M, Rifat A, Dip FT et al (2018) Multi-objective optimization of chip-tool interaction parameters using Grey-Taguchi method in MQL-assisted turning. Measurement 129:156-166. https://doi. org/10.1016/j.measurement.2018.07.014

19. Mukherjee I, Ray PK (2006) A review of optimization techniques in metal cutting processes. Comput Ind Eng 50:15-34. https://doi. org/10.1016/j.cie.2005.10.001

20. Abbas A, Pimenov D, Erdakov I, Taha M, el Rayes M, Soliman M (2018) Artificial intelligence monitoring of hardening methods and cutting conditions and their effects on surface roughness, performance, and finish turning costs of solid-state recycled aluminum alloy 6061 chips. Metals (Basel) 8:394. https://doi.org/10.3390/ met8060394

21. Abbas AT, Pimenov DY, Erdakov IN, Taha M, Soliman M, el Rayes M (2018) ANN surface roughness optimization of AZ61 magnesium alloy finish turning: minimum machining times at prime machining costs. Materials (Basel) 11. https://doi.org/10.3390/ ma11050808

22. Alam S, Dobbie G, Rehman SU (2015) Analysis of particle swarm optimization based hierarchical data clustering approaches. Swarm Evol Comput 25:36-51. https://doi.org/10.1016/j.swevo.2015.10. 003
23. Long Q, Wu C, Huang T, Wang X (2015) A genetic algorithm for unconstrained multi-objective optimization. Swarm Evol Comput 22:1-14. https://doi.org/10.1016/j.swevo.2015.01.002

24. Agrawal SK, Sahu OP (2014) Author's accepted manuscript artificial bee colony algorithm to design two-channel quadrature. Swarm Evol Comput 21:24-31. https://doi.org/10.1016/j.swevo.2014.12.001

25. Satapathy SC, Naik A (2014) Modified teaching-learning-based optimization algorithm for global numerical optimization - a comparative study. Swarm Evol Comput 16:28-37. https://doi.org/10. 1016/j.swevo.2013.12.005

26. Scheffer C, Kratz H, Heyns PS, Klocke F (2003) Development of a tool wear-monitoring system for hard turning. Int $\mathrm{J}$ Mach Tools Manuf 43:973-985. https://doi.org/10.1016/S0890-6955(03) 00110-X

27. El-Mounayri H, Dugla Z, Deng H (2003) Prediction of surface roughness in end milling using swarm intelligence. In: Proc. 2003 IEEE Swarm Intell. Symp. SIS'03 (Cat. No.03EX706). pp 220-227

28. Oktem H, Erzurumlu T, Erzincanli F (2006) Prediction of minimum surface roughness in end milling mold parts using neural network and genetic algorithm. Mater Des 27:735-744. https://doi.org/10. 1016/j.matdes.2005.01.010

29. Abhishek K, Rakesh Kumar V, Datta S, Mahapatra SS (2017) Parametric appraisal and optimization in machining of CFRP composites by using TLBO (teaching-learning based optimization algorithm). J Intell Manuf 28:1769-1785. https://doi.org/10.1007/ s10845-015-1050-8

30. Li D, Zhang C, Shao X, Lin W (2016) A multi-objective TLBO algorithm for balancing two-sided assembly line with multiple constraints. J Intell Manuf 27:725-739. https://doi.org/10.1007/ s10845-014-0919-2

31. Yu K, Wang X, Wang Z (2016) An improved teaching-learningbased optimization algorithm for numerical and engineering optimization problems. J Intell Manuf 27:831-843. https://doi.org/10. 1007/s10845-014-0918-3

32. Chen D, Lu R, Zou F, Li S (2016) Teaching-learning-based optimization with variable-population scheme and its application for ANN and global optimization. Neurocomputing 173:1096-1111. https:// doi.org/10.1016/j.neucom.2015.08.068

33. Sanz A, Negre AA, Fernández R, Calvo F (2013) Comparative study about the use of two and three-dimensional methods in surface finishing characterization. Procedia Eng 63:913-921. https:// doi.org/10.1016/j.proeng.2013.08.267

34. Poletika MF (1969) Contact loads on tool faces (Russian). Machinostronie, Moscow

35. Rao RV, Kalyankar VD (2013) Experimental investigation on submerged arc welding of Cr-Mo-V steel. Int J Adv Manuf Technol 69:93-106. https://doi.org/10.1007/s00170-013-5007-9

36. Garg A, Lam JSL (2016) Modeling multiple-response environmental and manufacturing characteristics of EDM process. J Clean Prod 137:1588-1601. https://doi.org/10.1016/j.jclepro.2016.04.070

37. Gupta MK, Sood PK, Sharma VS (2016) Investigations on surface roughness measurement in minimum quantity lubrication turning of titanium alloys using response surface methodology and Box - Cox transformation. J Manuf Sci Prod 16. https://doi.org/10.1515/jmsp2015-0015 